\title{
Zimbabwe (and Uganda): lessons from Africa!
}

\author{
Filippo Ciantia
}

Received: 18 April 2011 / Accepted: 27 May 2011 / Published online: 6 July 2011

(C) Springer-Verlag 2011

The XVII International AIDS Conference held in August 2008 in Mexico City was the biggest event ever dedicated to HIV/AIDS taking place in Latin America. In the late afternoon of Monday the 4th of August, a satellite session was dedicated to the successful story of Zimbabwe [1]. The meeting was jointly organized by UNFPA Zimbabwe, the National AIDS Council, the Ministry of Health and Child Welfare and UNAIDS Zimbabwe. Zimbabwe was the first country in Southern Africa, the most affected region of the continent, to register a significant decline in HIV prevalence. This unexpected fall was investigated through different sources and methodologies, such as ante natal clinics surveillance, cohort studies and population-based surveys. The prevalence in the 15- to 49-year-old group peaked in late $1990 \mathrm{~s}$ at $29.3 \%$, then leveled off and finally declined after 2001 to $15.6 \%$ in 2007.

However, the story of this extraordinary result was narrated in a small and late in the day satellite session. Moreover, the result was achieved in a country plagued by poverty and civil and political unrest and therefore with very limited resources and external support.

During the session Daniel Halperin, who investigated the qualitative role of programmes and the social environment in Zimbabwe's HIV decline, and Bruce Campbell, the country representative of the UNFPA, identified the success factors in the inclusive strategy, similar to the Ugandan methodology, open to all actors and without ideological barriers. Halperin noted that that the attitude of the Zimbabwean resembled the approach of Ugandans to the devastating epidemic of the 1980s in the tiny Eastern

F. Ciantia $(\bowtie)$

Department of International Affairs, Expo 2015 SpA,

Via Rovello, 2, 20121 Milan, Italy

e-mail: filippo.ciantia@gmail.com
Africa country. People were motivated to survive and to take care of the sick and even of the orphans by the conviction that their children, their families still needed them. The spread of AIDS could be prevented and it was possible for each individual to contribute to this effort: living positively with AIDS was imaginable and it was a socially useful contribution to the fight against the epidemic.

Therefore, the recent publication by the online medical journal PLoS Medicine of the article "A surprising prevention success: why did the HIV epidemic decline in Zimbabwe?" did not take me by surprise [2]. Actually, it might appear rather strange that the publication about what happened in Zimbabwe on a peer-reviewed open-access journal distributed by the public science library could happen more than 2 years after the presentation in Mexico City! In fact, the advert of the satellite session literally declared that the decline had been well documented and was confirmed. However, the reasons of what happened in Zimbabwe justify this anomalous delay! Actually prior to Mexico City conference, two major publications about the decline of HIV in Zimbabwe went practically unnoticed [3, 4], despite the AIDS ambassador Mark Dybul's remarks on these unexpected trends: "Perhaps one of the most interesting things is that the greatest behavior change was in abstinence and fidelity. The relative change in condom use was as not as remarkable" [5].

The prevalence in Zimbabwe declined by $13 \%$ from 1997 to 2007 , from 29 to $16 \%$, mainly driven by a reduction in extramarital, casual and commercial, sexual partners. Zimbabwe's success story points to the power of social change and the need for more detailed analyses of HIV success stories in Africa. Halperin compared it to the role of partner reduction in the fight against HIV in Uganda, which promoted a reduction in concurrent 
partnerships as the key focus of its HIV prevention campaigns in the late 1980s and early 1990s [6].

This article underlines the factors that allowed Zimbabwe to achieve, with limited resources, the results that neighboring countries of southern Africa could not yet register.

First of all in Zimbabwe there was a clearer understanding and acceptance that HIV is a sexually transmitted disease. And we well know that this was not easily recognized in the region. This led to tailored communication, prevention and education campaigns addressing the whole population. Qualitative studies found that behavior change resulted primarily from increased interpersonal communication about HIV due to high personal exposure to AIDS mortality and a correct understanding of sexual HIV transmission, due to relatively high education levels and probably also to information provided by HIV programs [7, 8].

A second powerful factor of change has been the greater ability to act upon "be faithful" messages, given the stronger marriage pattern in Zimbabwe than in that in neighboring countries, also having well-educated populations, such as Botswana and South Africa.

Finally, information was received through existing social networks: friends, extended family, communities, churches, local civil and traditional authorities, with a strong interpersonal mark. Data from an HIV research site in Zimbabwe's Manicaland province showed that the number of men who reported having multiple concurrent partners fell by $40 \%$ between about 1998 and 2003, roughly the same time period in which the number of new HIV infections was falling rapidly and salaries in the country fell by about $90 \%$.

Therefore, a phenomenon of social cohesion was created with intriguing similarities with the social networks built up in Uganda where seroprevalence declined from 20 to $6 \%$ in the $1990 \mathrm{~s}$, through a strategy of primary prevention focused on delay of sexual debut and reduction of number of casual partners. Several published studies showed that the major factor for the decline of prevalence of HIV in Uganda was the reduction in casual, multi-partners sex [911]. Since then, evidence for a pivotal role for partner reduction, complemented by decline in premarital sex, has emerged for more recent HIV declines in Kenya, Zimbabwe, Ethiopia and Malawi. In Uganda, Kenya, and Zambia increases in abstinence behaviors have been associated with declines in HIV prevalence. In Uganda the percent of youth aged 15-24 years reporting pre-marital sex in the past year declined from 53 to $16 \%$ for females and 60 to 23\% for males between 1989 and 1995 [12, 13]. In Kenya, similar declines in pre-marital sexual activity in the past year were seen, from 56 to $41 \%$ for males and from 32 to $21 \%$ for females, aged 15-24 years, between 1988 and 1993 [14]. All successful stories in Africa have been preceded by declines in casual sex and in premarital sex, in general registered over 5-6 years before the evidence of decline [15-22].

Despite the publication, with difficulties and "strange" delays, of these results by authoritative medical journals, the evidences gathered in Uganda in the 1990s and in Zimbabwe in the early years of the new millennium, are still forgotten and battled [23-25].

Two new books of Edward C Green have been recently published [26, 27]. In "Broken promises: How the AIDS establishment has betrayed the developing world", Ted Green describes his personal path of in depth understanding of the prevention of HIV/AIDS in Subsaharan Africa and Central America. He finally found himself, "a lifelong, outspoken liberal-progressive leftist", perfectly in agreement with Pope Benedict XVI, when in spring 2009, flying to Africa on Shepard One affirmed "the scourge (of AIDS) can't be resolved with the distribution of condoms: on the contrary, there is a risk of increasing the problem" [28]. Green offers a well-documented and fascinating original key to the understanding of the global AIDS epidemic. It is necessary to avoid easy stereotypes and prejudices and slogans, to face in a constructive way an epidemic still affecting millions. The worldwide crises we are facing in this very period of history do not allow us to delay again the implementation of effective, evidence-based and cheap strategies to fight HIV/AIDS, as Zimbabwe and Uganda have shown us $[29,30]$. Any delay or refusal would represent gifts to the disease.

Conflict of interest I declare that I do not have any conflict of interest, save for a deep love for Africa and her peoples. I am therefore profoundly happy that Africans can offer a lesson to the world about the solution of a global and tragic pandemic.

\section{References}

1. The Sharpest HIV Decline in Southern Africa: Experiences from Zimbabwe. http://www.aids2008.org/Pag/PSession.aspx?s=514. Accessed 12 Mar 2011

2. Halperin DT, Mugurungi O, Hallett TB, Muchini B, Campbell B et al (2011) A surprising prevention success: why did the HIV epidemic decline in Zimbabwe? PLoS Med 8(2):e1000414. doi:10.1371/journal.pmed.1000414. http://www.plosmedicine. org/article/info\%3Adoi\%2F10.1371\%2Fjournal.pmed.1000414. Accessed 12 Mar 2011

3. UNAIDS (2005) Evidence for HIV declines in Zimbabwe: a comprehensive review of the epidemiological data. Geneva: UNAIDS, http://data.unaids.org/publications/irc-pub06/ zimbabwe_epi_report_nov05_en.pdf. Accessed 8 Apr 2011

4. T B Hallett, J Aberle-Grasse, G Bello et al (2006) Declines in HIV prevalence can be associated with changing sexual behaviour in Uganda, Zimbabwe and urban Haiti. Sex Transm Infect 82:i1-i8. doi:10.1136/sti.2005.016014

5. Erika Check, Infection in Zimbabwe falls at last. BioEd Online http://www.bioedonline.org/news/news.cfm?art=2318. Accessed 8 Apr 2011 
6. Plus news-Zimbabwe: lessons in HIV prevention http://www. plusnews.org/Report.aspx?Reportid=91901. Accessed 12 Mar 2011

7. Muchini B, Benedikt C, Gregson S, Gomo E, Mate R et al (2010) Local perceptions of the forms, timing and causes of behavior change in response to the AIDS epidemic in Zimbabwe. AIDS Behav 15(2):487-498

8. Hargreaves JR, Bonell CP, Boler T, Boccia D, Birdthistle I et al (2008) Systematic review exploring time trends in the association between educational attainment and risk of HIV infection in subSaharan Africa. AIDS 22:403-414

9. Stoneburner RL, Low-Beer D (2004) Population-level HIV declines and behavioral risk avoidance in Uganda. Science 304:714-718

10. Green EC, Halperin DT, Nantulya V, Hogle JA (2006) Uganda's HIV prevention success: the role of sexual behavior change and the national response. AIDS Behav 10:335-346

11. Shelton JD, Halperin DT, Nantulya V, Potts M, Gayle HD et al (2004) Partner reduction is crucial for balanced 'ABC' approach to HIV prevention. BMJ 328:891-893

12. Bessinger R, Akwara P, Halperin D (2003) Sexual behavior, HIV and fertility trends: a comparative analysis of six countries; phase I of the ABC study. Meas Evaluation, Chapel Hill, NC

13. Cheluget B, Baltazar G et al (2006) Evidence for population level declines in adult HIV prevalence in Kenya. Sex Transm Infect 82(1):i21-i26

14. Kenya demographic and health survey (2003) http://www. measuredhs.com/pubs/pdf/FR151/FR151.pdf. Accessed 12 Mar 2011

15. Uganda demographic and health survey (2006) http://www. measuredhs.com/pubs/pdf/SR126/SR126.pdf. Accessed 12 Mar 2011

16. Uganda demographic and health survey (2006) http://www. measuredhs.com/countries/metadata.cfm?surv_id=266\&ctry_id= 44\&SrvyTp=ctry\&cn=Uganda. Accessed 12 Mar 2011

17. Zimbabwe demographic and health survey (2005-2006) http://www.measuredhs.com/pubs/pdf/FR186/FR186.pdf. Accessed 12 Mar 2011
18. Zimbabwe demographic and health survey (2005-2006) http://www.measuredhs.com/pubs/pdf/FR186/ZimbabweErrata.pdf. Accessed 12 Mar 2011

19. Tanzania Demographic and Health Survey (2007-2008) http:// www.measuredhs.com/countries/metadata.cfm?surv_id=304\&ct ry_id=39\&SrvyTp=ctry\&cn=Tanzania. Accessed 12 Mar 2011

20. Malawi demographic and health survey (2004) http://www. measuredhs.com/pubs/pdf/FR175/FR-175-MW04.pdf. Accessed 12 Mar 2011

21. Malawi demographic and health survey (2004) http://www. measuredhs.com/pubs/pdf/HF7/Malawi_HIV_factsheet.pdf. Accessed 12 Mar 2011

22. Green EC, Herling A (2006) Paradigm Shift and Controversy in AIDS Prevention. J Med Pers 4:23-33

23. PlusNews-Global HIV/AIDS news and analysis. HIV/AIDS: tracing the multiple concurrent partner debate http://www. plusnews.org/report.aspx?Reportid=90800. Accessed 12 Mar 2011

24. PlusNews-Global HIV/AIDS news and analysis. Africa: falling HIV rates tell complex story http://www.plusnews.org/ report.aspx ?Reportid=90800. Accessed 12 Mar 2011

25. Plus News-Global HIV/AIDS news and analysis. Zimbabwe: drop in condom use following HIV prevention trial http://www. plusnews.org/Report.aspx?ReportId=91147. Accessed 12 Mar 2011

26. Green EC (2011) Broken promises: how the AIDS establishment has betrayed the developing world. PoliPoint Press 288

27. Green EC, Ruark AH (2011) AIDS, behavior, and culture: understanding evidence-based prevention (key questions in anthropology). Amazon.com http://www.amazon.com/AIDSBehavior-Culture-Understanding-Evidence-Based/dp/1598744798/ ref=sr_1_2?s=books\&ie=UTF8\&qid=1297933521\&sr=1-2

28. Benedict XVI (2009) Press conference on route to CameroonOur Faith is Hope by definition. http://www.zenit.org/article25405? l=english Accessed 12 Mar 2011

29. Ciantia F, Pariyo GW, Giusti D et al (2008) The Pope and science. Lancet 371(9618):1069

30. Ciantia F, Orach S, Pariyo GW, Busingye R et al (2009) HIV prevention conundrum: did the Pope have a case? J Med Pers 7(2):63-69 